\title{
DAMAGE; OPERATION AND REINSTATEMENT OF POST OFFICE COMMUNICATIONS SERVICES
}

\author{
D. C. A. Eddy* B. B. Hands* D. S. G. Preston*
}

The area of the West Coast affected by the earthquake lies within the Greymouth Post Office Engineering District controlled by a District Engineer at Greymouth and within the districts controlled by the Chief Postmasters at Greymouth and Westport.

The Buller Gorge lies within the Nelson and Greymouth Engineering Districts which are divided at Lyell。

Telephone exchanges affected by the earthquake were the manual exchange of 1200 lines at Hokitika, an automatic exchange network of nine exchanges comprising 4100 lines in and around Greymouth; a 500-line manual exchange at Reefton; a 50-line automatic exchange at Inangahua Junction having links to Reefton, westport and Murchison; an automatic and manual exchange network at Westport comprising three exchanges with 2060 lines, a 100-line manual exchange at Karamea and a manual exchange at MurchisonoReticulation of lines from the exchanges to subscribers premises is largely by cable with short end sections of aerial line except in rural areas where long aerial lines predominate。

\section{Subscribers}

Subscribers telephones out of action at Holkitika numbered 100, at Greymouth 700, at Reefton 120, at Westport 800 and a number at Murchison. Line gangs were diverted from normal duties to fault clearance which comprised mostly the untangling of aerial lines twisted together during the major and after shocks. The faults were easily remedied by freeing the wires and were mostly cleared by the end of the day. No engineering staff are stationed at Inangahua Junction and the description of. restoration there is covered separately.

\section{Toll lines}

Fault location testing of inoperative toll lines was commenced by $6 \mathrm{a}, \mathrm{m}$. and linestaff were being directed to the affected areas by 6.15 $a \cdot m$. Ilowever, the restoration of toll lines proved a formidable task and of the disrupted lines between Greymouth-Reefton, Reefton-Inangahua Junction, Inangahua Junction-Westport, Inangahua Junction-Murchison and Westport-Karamea, only the Greymouth-Reefton lines were restored on the day of the earthquake, this being effected at 2.40 pom。 Road access along the other routes was not possible for some time and delayed restoration.

One toll line from Reefton terminated on a telephone at Inangahua Junction was provided on Sunday 26 May。

\section{Restoration}

It became apparent on Nonday 27 May that additional resources would 
be necessary to carry out restoration work and a Field Eninineer from Christchurch who had a good knowledge of the liest coast was sent inmediately. He was stationed at leefton for three weeks and worked closely with Civil Defence iuthorities. Two line and one cable rang from Christchurch were sent to Reefton and Inangahua Junction while Murchison linestaff were augmented from the Nelson area。

Damage to the Westport telephone exchange was minor and was limited to the battery and engine alternator equipment。

At Inangahua Junction the small exchange building was twisted on its foundations, and although the automatic equipment inside moved approximitely two feet it was in working order. Owing to extensive line damage no telephones were worlsing. Outside contact was lost because of toll. line dimage.

one and a half miles of underground cabling was abandoned in the Inangahua Junction area as the cable was bidly damaged by 80 srround subsidences and cracks。 It has been replaced by self-supiorting aerial cable installed on existing poles.

The post office and exchange buildings were threatened by a large slip and the buildings were shifted to a new site by 9 June 1968 .

The Reefton Post Office, built of brick, wis bidly dimeged and had to be demolished on 5 June 1968. Fortunctely the portion containing the exchange equimment was undmaged and was able to be retained in service long enough for a replacement exchange and carrier room to be assenbled in a portable building in Christchurch by technicians working $24120 m s$ a day in shifts, trunsported to leefton and instilled on the new site. Diversion of wixing rrom the old to the new exchinge commonced innciately and was completed when the replacoment exchinge arrivedo

The peak number of starf enguged in the iroa was 67 .

Some minor damage (bolts wenched from walls and coilinf) occurred in the Greymouth exchange buildiry, scoustio tiles rell from the ceiline in the Telegraph operating room on top of the teleprinters, but were quickly cleared away by $9 \mathrm{a}, \mathrm{m}$ 。

Major damage to Post office plant occurred in the Usper Suller Gorge due to slips immediately following the earthquake and curther slips rlue to heavy rain in the area.

The lower Buller Gorge road was opened on 1 June 1968 and tire Westport-Inangahua Junction toll line was restored on 2 June 1968,

Additional staff were sent to Hurchison by the District Encineer, Nelson early on the morning of the earthquake and throughout the day they concentrated on restorine local subscribers services. it this stage access to the Upper Buller Gorge was blocked to all vehicles.

During the day an attempt was made to survey the ;orge from a Cessna aeroplane but because of low visibility this was unsuccessful. On Saturday, 25 May a helicopter cirrying a tost Office lssistant ingineer and Overseer made a successful survey.

Because of the dunger to men due to the unstable country a sturt was not made until Monday, 27 May when men conmenced working from the Murchison and Inangahua Junction ends. Throughout ilonday and Tuesday a helicopter was used from the jurchison end to ferry men and material from Murchison and Inangahua Junction past the numerous slipso Photographs enclosed show the conditions under which restoration work was carried out。

Unfortunately on fednesday, 29 May the first flight crashed and the pilot and two Post office men were killed. 
A temporary line was put through from Murchison to Inangahua Junction on $14 \mathrm{June} 1968$, approximately two months before the road was opened. It has been subject to interruption since then due to road restoration work and fallin. debris. The permanent line was expected to be completed in september 1968, but has further damage resulting from heavy rain causing slips to move。

\section{Toll traffic}

A record number of calls were handled on the day of the earthquake and delays up to 6 hours on to 11 calls to the West Coast were experienced on the days following the earthquake. The exceptionally high calling rate and the loss of 20 circuits on the Buller Gorge route caused the delays.

The Post Office emergency radio stations at Vestport and Karamea provided the only link to Karamea until the toll line was restored at 5.30 pom。 on 26 May 1968 。

\section{Summary}

Damage to automatic and manual switching and carrier equipment was of a very minor nature even at Inangahua Junction. Restoration of extensive faults due to wrapping of wires on subscribers lines was easily achieved。

Damage to the exchange building at Reefton necessitated a major effort to establish a new exchange in the shortest possible time。 However, all modern exchange buildings are built to withstand earthquakes and future trouble on this account is unlikely. Pole lines were extensively damaged by slips and restoration involved work of major proportions。

Telegraph circuits in the area were not greatly affected although service to Reefton, Westport, and Karamea was interrupted for varying periods.

Mails for Westport from the North Island and the Nelson and Marlborough areas had to be re-routed because of the closing of the Buller Gorge. Inward mails from Christchurch and southern offices were little affected by the earthquake. Postmen's deliveries operated as usual.

All outward mail also had to be routed through Greymouth.

\section{Acknowledgement}

The authors thank the Director-General of the Post Office for permission to publish this paper. 


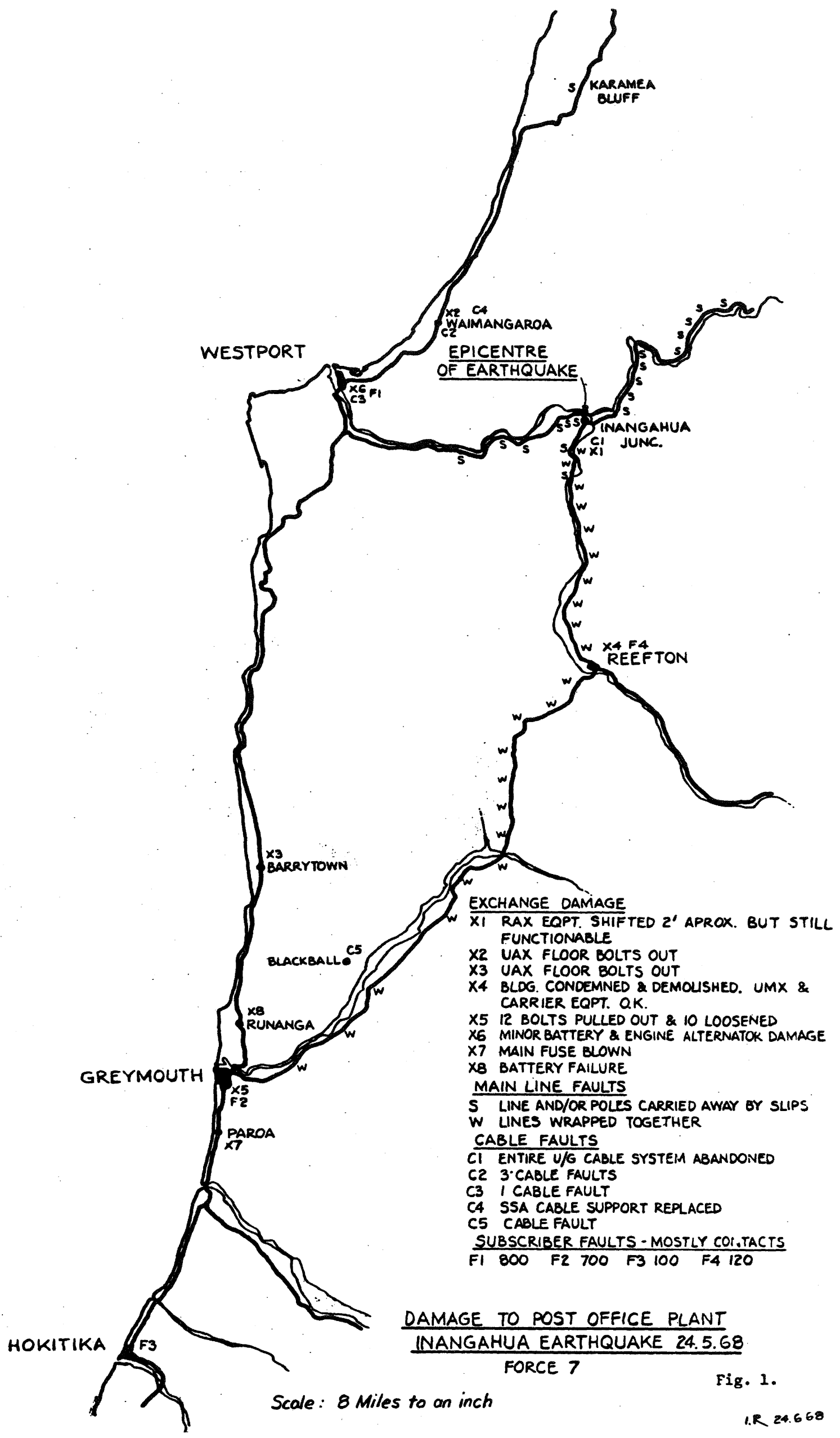




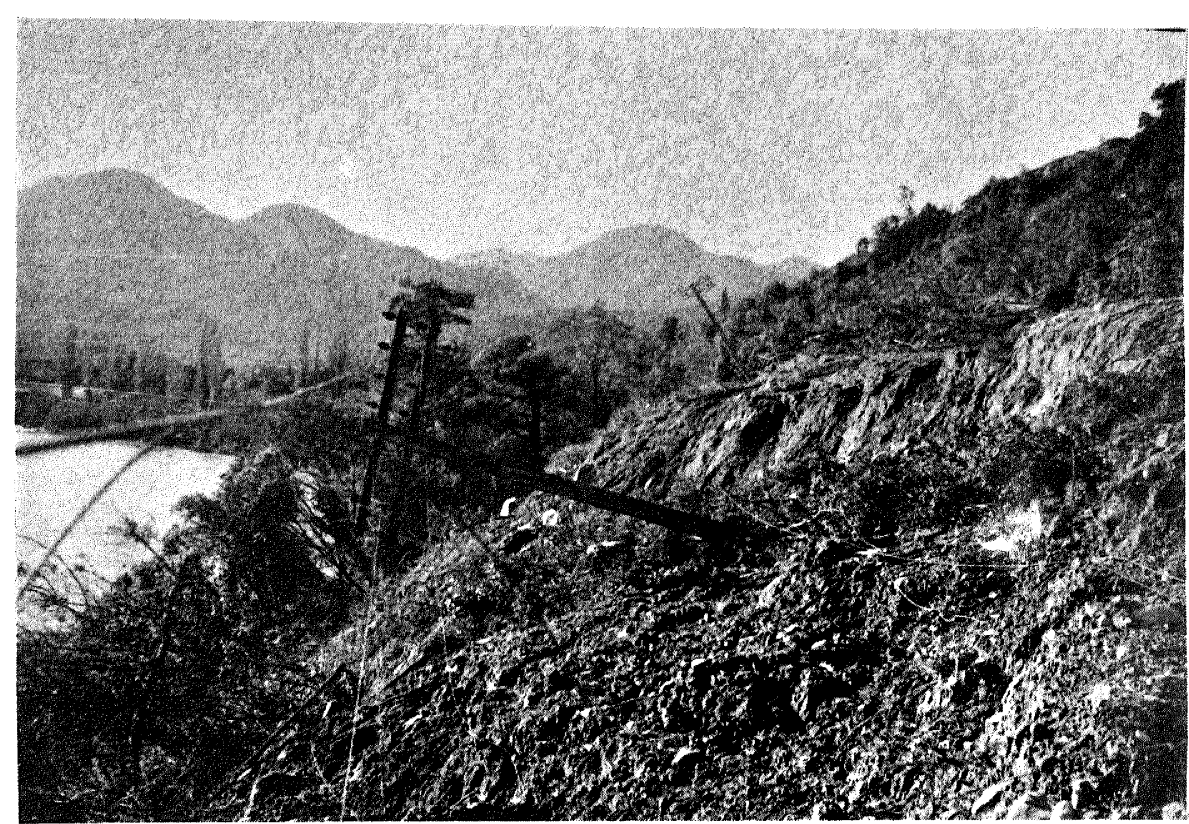

Fig. 2. Typical damage to poles near New Creek, at $8 \frac{7}{2}$ miles up the Buller Gorge from Inangahua Junction.

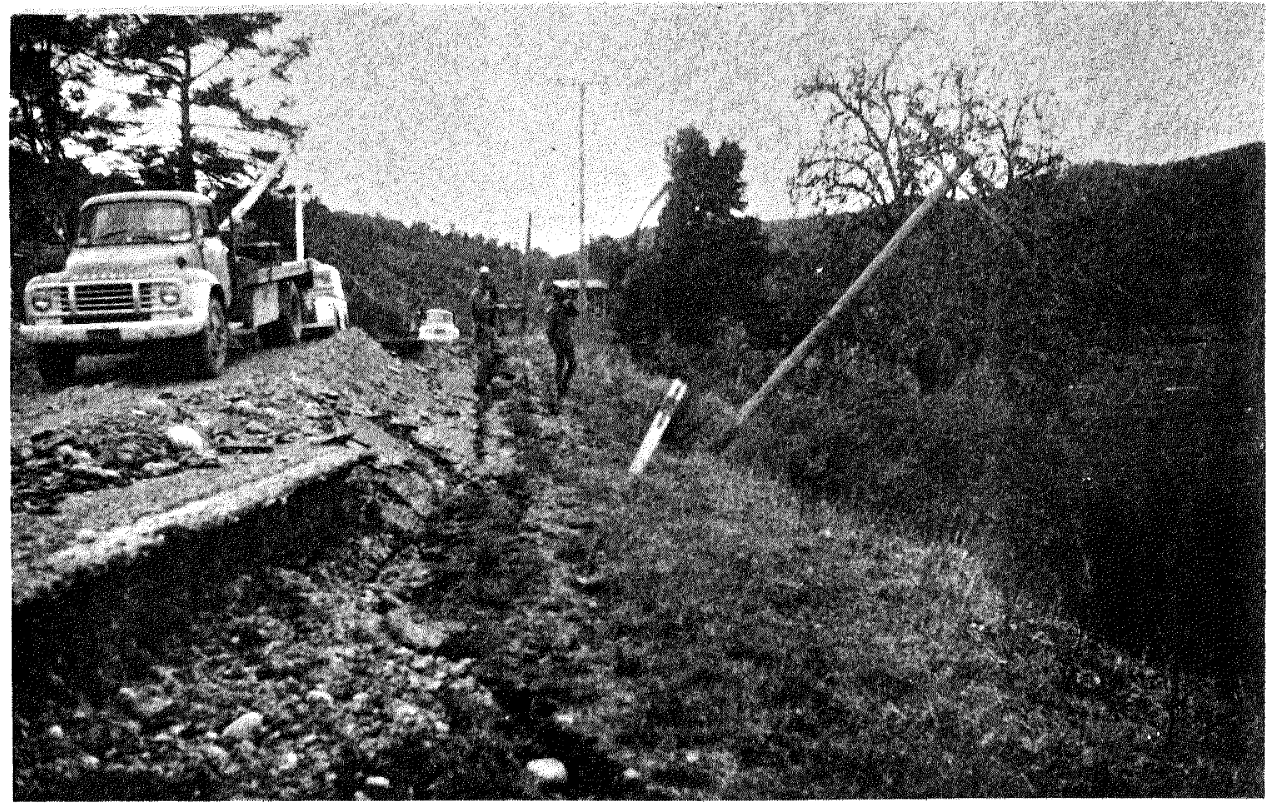

Fig. 4. Gang straightening poles which had fallen away with the ground next to the road at Three Channel Flat.

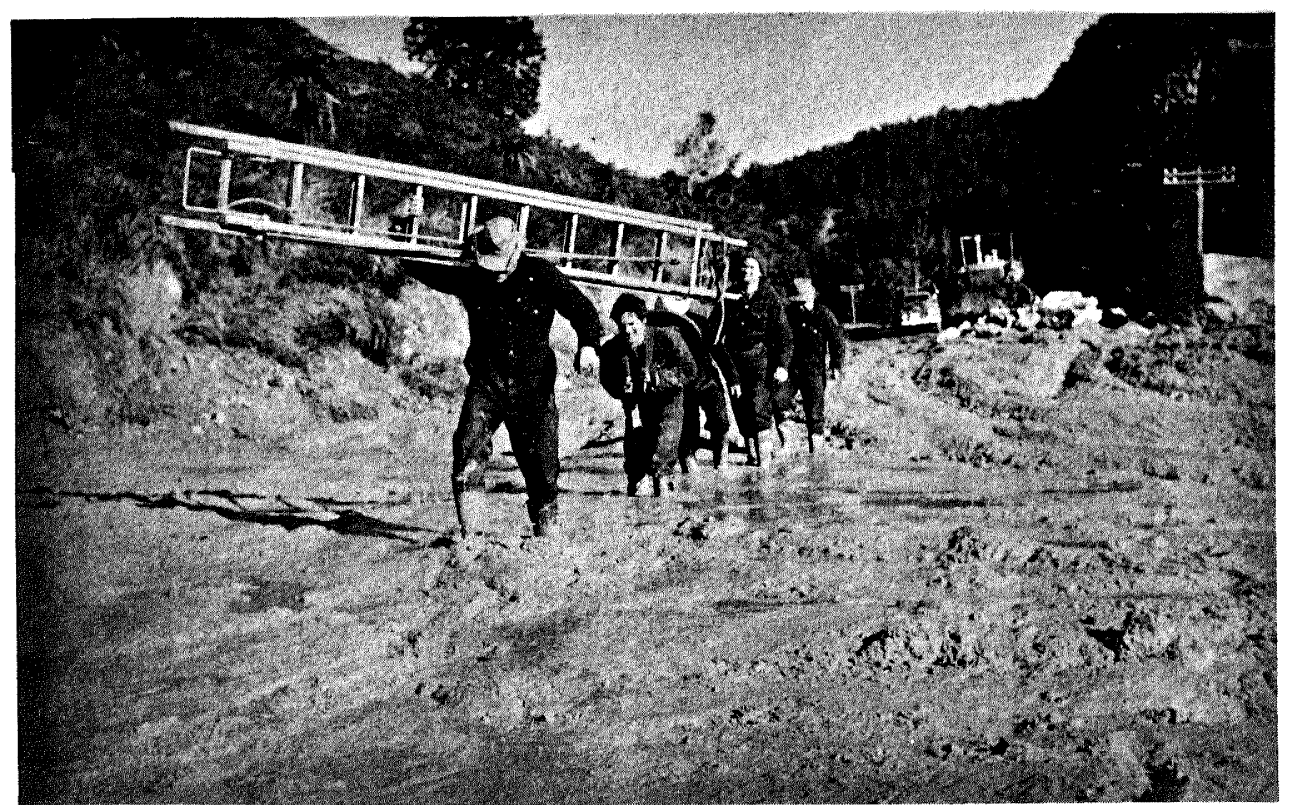

Fig. 3. Christchurch gang crossing a mud slip near Arnolds

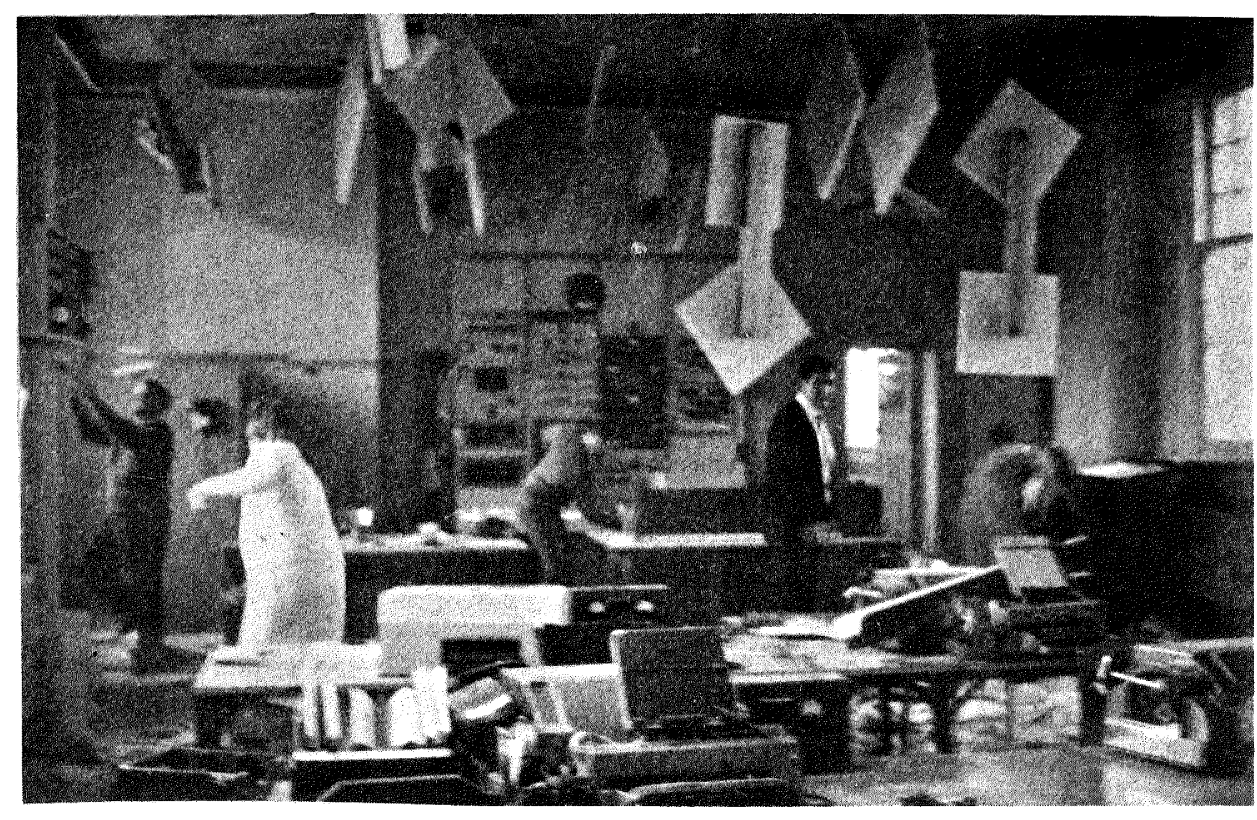

Fig. 5. Inside the Greymouth Telegraph Office showing Anmorer th onmanetin tiles on the ceiling. 